\title{
Tratamiento de un Efluente con Furfural mediante Bacterias Autóctonas, en un Reactor Anaerobio de Lecho Fluidizado
}

\section{Treatment of an Effluent with Furfural by Native Bacteria, in a Fluidized Bed Anaerobic Reactor}

Presentación: 19/01/2020

Aprobación: 29/04/2020

\section{Alejandro Farías}

Grupo de Investigación Sobre Temas Ambientales y Químicos (GISTAQ) - Facultad Regional Resistencia, Universidad Tecnológica Nacional - Argentina

alefarias@frre.utn.edu.ar

\section{Enrique Utgés}

Grupo de Investigación Sobre Temas Ambientales y Químicos (GISTAQ) - Facultad Regional Resistencia, Universidad Tecnológica Nacional - Argentina

eutges@hotmail.com

\section{Daniela Tenev}

Grupo de Investigación Sobre Temas Ambientales y Químicos (GISTAQ) - Facultad Regional Resistencia, Universidad Tecnológica Nacional - Argentina

mdtenev@gmail.com

\section{Elsa Hervot}

Grupo de Investigación Sobre Temas Ambientales y Químicos (GISTAQ) - Facultad Regional Resistencia, Universidad Tecnológica Nacional - Argentina

elsahervot@gmail.com

\section{Enid Utgés}

Grupo de Investigación Sobre Temas Ambientales y Químicos (GISTAQ) - Facultad Regional Resistencia, Universidad Tecnológica Nacional - Argentina

enidutges@gmail.com

\section{María Nocenti}

Grupo de Investigación Sobre Temas Ambientales y Químicos (GISTAQ) - Facultad Regional Resistencia, Universidad Tecnológica Nacional - Argentina

florencianocenti@gmail.com 


\title{
Resumen
}

El objetivo del presente trabajo fue proponer un tratamiento alternativo para los efluentes provenientes de una industria que fabrica furfural. El efluente, denominado aguas madres, contiene hasta $3000 \mathrm{mg} / \mathrm{L}$ de furfural. Para ello, se diseñó y construyó un reactor anaerobio de lecho fluidizado; se adaptaron microorganismos autóctonos al efluente a degradar y se evaluó la eficiencia, mediante el tratamiento de un efluente sintético de similares características que las aguas madres. Se monitoreó el desempeño del reactor, analizando los porcentajes de remoción de furfural. Los resultados, a escala laboratorio, demostraron que es posible adaptar consorcios bacterianos a concentraciones de furfural de hasta $600 \mathrm{mg} / \mathrm{L}$. El reactor ensayado resultó eficiente y pudo ser utilizado para evaluar la degradación del furfural. Se obtuvieron porcentajes de remoción de hasta 99,92\% en 20 horas de operación.

Palabras clave: Efluente, furfural, biorremoción, consorcio bacteriano, reactor anaerobio de lecho fluidizado.

\begin{abstract}
The aim of this study was to propose an alternative treatment for an effluent from a tannin's industry which contains up to $3000 \mathrm{mg} / \mathrm{L}$ of furfural. To achieve this, we designed and constructed an anaerobic fluidized-bed reactor at pilot scale; we made the adaptation of native bacteria to different concentrations of the effluent and evaluated the efficiency of the reactor by treating a synthetic effluent with similar characteristics. Laboratory scale results showed that it is possible to adapt bacteria at concentrations up to $600 \mathrm{mg} / \mathrm{L}$ of effluent. The designed reactor was efficient and could be used to assess degradation of furfural, obtaining $99,92 \%$ of removal after 20 hours of operation.
\end{abstract}

Keywords: Effluent, furfural, biodegradation, native consortia, anaerobic fluidized-bed reactor.

\section{Introducción}

El agua es un recurso natural vital y escaso, por el que consecuentemente compiten los sectores que integran las actividades humanas: agrícola-ganadero, industrial, doméstico, y ecosistemas que se ven perjudicados (Pagliettini, 2014: 16). En muchas ocasiones, se descargan efluentes líquidos sin un tratamiento adecuado a cuerpos naturales de agua. Esto, a nivel nacional y mundial, se ha transformado en uno de los problemas ambientales más difíciles de controlar y/o revertir.

El presente estudio, se realizó sobre los efluentes líquidos de una industria taninera y productora de furfural, localizada en La Escondida (provincia de Chaco). En la fabricación de furfural - un aldehído heterocíclico - la materia prima utilizada es el aserrín de quebracho colorado, luego de extraerle el tanino. El proceso genera, en una primera etapa, una cola de destilación denominada aguas madres (Crönert and Loeper, 1969). Los componentes principales de ésta son ácido acético y furfural residual, compuestos de características complejas que deben ser eliminados debido a su efecto tóxico sobre los seres vivos. Uno de los efectos informados por Ran et al. (2014) son los daños sobre la membrana plasmática y el metabolismo celular. No obstante, estudios efectuados por varios autores sobre concentraciones de furfural entre 2400 y $2880 \mathrm{mg} / \mathrm{L}$, indican ausencia de inhibición en el crecimiento de microorganismos (Brune et al., 1983; López et al., 2004; Boopathy, 2009; Wierckx et al., 
2010). Dada la potencial toxicidad del furfural presente en el efluente (International Furano Chemicals B.V., 2003) sobre organismos presentes en el cuerpo de agua receptor y, previo a su descarga, deberá ser tratado adecuadamente de acuerdo con los parámetros de vuelco estipulados en la Ley $\mathrm{N}^{\circ} 3230$ : "Código de Aguas" de la provincia del Chaco.

El Reactor Anaerobio de Lecho Fluidizado, RALF, es un sistema biológico trifásico (gas - líquido - sólido) que contiene un soporte inerte sobre el que se adhiere la biomasa, formando un biofilm (Hidalgo et al., 2002). Los RALF, son aptos para operar con altos valores de carga orgánica, especialmente efectivos en el tratamiento de aguas con compuestos recalcitrantes, favorecen el transporte de células microbianas del seno del líquido a la superficie del soporte, incrementando así el contacto microorganismo-sustrato (Pérez et al., 1998). Además, se ven menos afectados por interrupciones y condiciones adversas de operación que otros reactores (Farhan et al., 1997).

Un RALF consta de un tubo cilíndrico, en cuyo interior hay un lecho de material poroso a través del cual circula el efluente líquido a tratar de manera ascendente y con la velocidad necesaria como para generar la fluidización. La Figura 1, muestra un esquema del RALF.

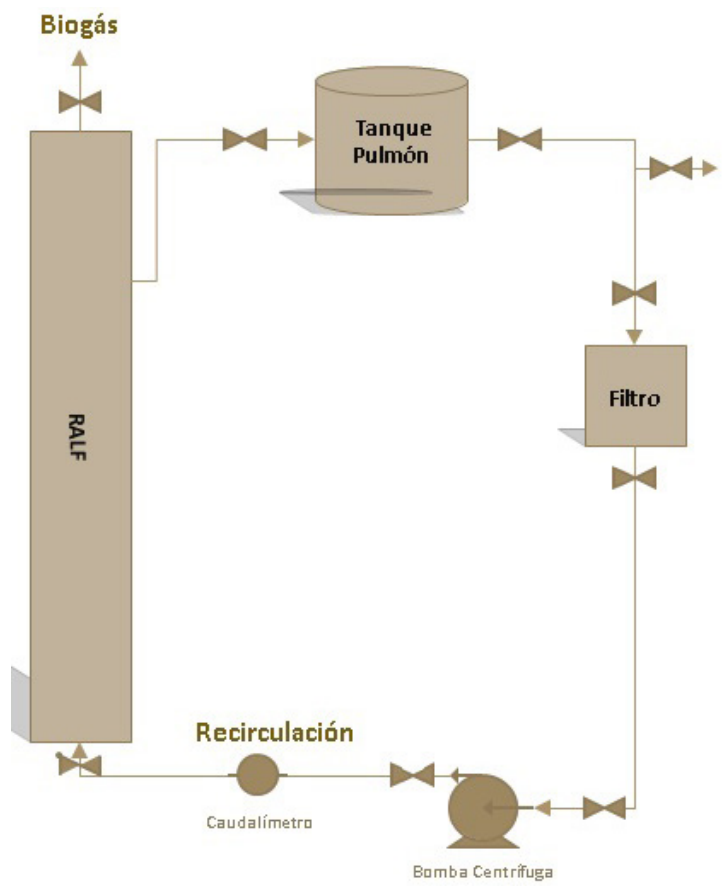

Figura 1. Esquema del Reactor Anaerobio de Lecho Fluidizado

El efluente, impulsado por una bomba, ingresa por la parte inferior del equipo. Se lo recircula para que el proceso sea continuo y mantenga una óptima velocidad de fluidización. El biogás producido y el efluente tratado egresan del sistema por la parte superior.

En el RALF propuesto, la remoción es efectuada por un consorcio microbiano autóctono; éste provino de los lodos del fondo de las lagunas sedimentadoras del sistema de tratamiento de efluentes de la fábrica, zona impactada directamente por el furfural.

Incrementar la eficiencia en la eliminación de compuestos tóxicos de un efluente industrial, depende casi exclusivamente de la aclimatación del consorcio microbiano, previo a 
su inoculación al reactor. Debe ser adaptado a un medio con una fuente de carbono principal (sustrato a degradar en concentraciones crecientes), un co-sustrato (fuente de carbono adicional) y enriquecido con fósforo, nitrógeno y minerales. Esas condiciones aumentan el rendimiento del proceso (Pishgar et al., 2014).

El objetivo de este trabajo fue diseñar y construir un RALF para, posteriormente, evaluar su eficiencia - a partir de ensayos de remoción de un efluente sintético con furfural - usando bacterias autóctonas previamente aclimatadas.

\section{Materiales y métodos}

\section{Caracterización de las aguas madres}

Se efectuaron tres testeos del efluente aguas madres, proveniente de la fabricación de furfural, para caracterizarla fisicoquímica y bacteriológicamente. Durante los tres meses en los que la planta operó normalmente, se extrajeron muestras desde un grifo situado a la salida de la primera columna de destilación. Se recolectaron 20 litros en frascos de vidrio con tapa a rosca, resistentes a temperaturas de $100{ }^{\circ} \mathrm{C}$ y de color ámbar oscuro para minimizar la oxidación del furfural, presente en las aguas madres, por acción de la luz solar (Zengh et al., 2015). Todas las muestras fueron remitidas inmediatamente al laboratorio de investigación del GISTAQ y conservadas siguiendo los protocolos de análisis correspondientes. Los ensayos analíticos se efectuaron según métodos normalizados (o adaptación de los mismos) de APHA, AWWA \& WEF (2005).

Los parámetros fisicoquímicos y bacteriológicos analizados en las aguas madres fueron: $\mathrm{pH}$ (peachímetro HANNA), Conductividad (conductímetro OAKTON), Color y turbiedad

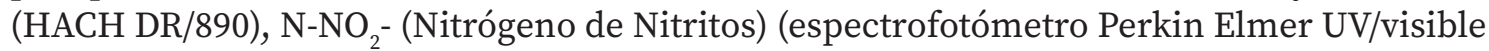
Lambda 25), Sólidos Totales (ST; evaporación de la muestra hasta peso constante en estufa eléctrica a $103-105^{\circ} \mathrm{C}$ ) y Volátiles (calcinación de la muestra en un horno mufla ORL a $500^{\circ} \mathrm{C}$ ), COT (Carbono Orgánico Total), $\mathrm{DBO}_{5}$ (Demanda Biológica de Oxígeno a 5 días; incubación a $2{ }^{\circ} \mathrm{C}$ por 5 días), DQO (Demanda Química de Oxígeno; digestión ácida y medición espectrofotométrica), recuento de bacterias Coliformes Totales (CT) y Fecales (CF) (incubación a $37{ }^{\circ} \mathrm{C}$ y $44{ }^{\circ} \mathrm{C}$ respectivamente en caldo Mac Conkey 48 h) y concentración de Furfural por Cromatografía Líquida de Alto Desempeño (HPLC) en un equipo Shimadzu CBM 20 A, cuyas características fueron: detector UV SPD 20 A y columna de fase inversa $\mathrm{C} 18$ a $40{ }^{\circ} \mathrm{C}$ de temperatura. La velocidad de flujo empleada fue de $1 \mathrm{~mL} / \mathrm{min}$ para un volumen de inyección de 20 $\mu \mathrm{L}$ y con una mezcla de acetonitrilo - agua tridestilada (17,5:82,5), como fase móvil. 
Los ensayos se resumen en la Tabla 1:

\begin{tabular}{|c|c|}
\hline Determinaciones & Métodos \\
\hline $\mathrm{pH}$ & $S M * 4500-H+B$ \\
\hline Conductividad $(\mu \mathrm{S} / \mathrm{cm})$ & $S M * 2510 B$ \\
\hline Turbiedad (NTU) & Hach**8237 \\
\hline Color (Pt-Co) & Hach** 8025 \\
\hline $\mathrm{N}-\mathrm{NO}_{2}^{-}(\mathrm{ppm})$ & $\mathrm{SM} * 4500-\mathrm{NO}_{2}-\mathrm{B}$ \\
\hline DQO (ppm) & $S M * 5220 \mathrm{D}$ \\
\hline $\mathrm{DBO}_{5}(\mathrm{ppm})$ & $S M * 5210 B$ \\
\hline COT (ppm) & $S M * 5310 \mathrm{D}$ \\
\hline Sólidos Totales (mg/L) & $S M * 2540 \mathrm{~B}$ \\
\hline Coliformes Totales CT (NMP/100mL) & $S M * 9221 B$ \\
\hline Coliformes Fecales CF (NMP/100mL) & $S M * 9221 \mathrm{C}$ \\
\hline
\end{tabular}

Tabla 1. Ensayos-métodos normalizados. *Standard methods; **Método HACH adaptado de Standard Methods for the Examination of Water \& Wastewater.

Aclimatación de consorcios bacterianos a concentraciones crecientes de furfural en aguas madres

Los consorcios bacterianos utilizados en los ensayos de adaptación se extrajeron de los lodos del sistema de tratamiento de la fábrica (Farías et al., 2015).

El inóculo bacteriano se preparó suspendiendo aproximadamente $4 \mathrm{~g}$ de lodos en un Erlenmeyer con solución de peptona de carne al 1\% m/v (Fernández Linares et al., 2006), en condiciones de esterilidad. Los nutrientes fueron: soluciones de cloruro de amonio $\left(\mathrm{NH}_{4} \mathrm{Cl}\right)$ al 12,7 \% m/v (J.T. Baker Inc. al 99,7 \% de pureza) y de fosfato diácido de sodio $\left(\mathrm{NaH}_{2} \mathrm{PO}_{4}\right)$ al $3,28 \% \mathrm{~m} / \mathrm{v}$ (Mallinckrodt Chemical Works, al $99 \%$ de pureza). El cloruro de amonio $\left(\mathrm{NH}_{4} \mathrm{Cl}\right)$ (Boopathy and Daniels,1991) se eligió como fuente de nitrógeno asimilable; el fosfato diácido de sodio $\left(\mathrm{NaH}_{2} \mathrm{PO}_{4}\right)$ como solución buffer y para proporcionar fósforo (Hareland et al.,1975); la peptona de carne, fuente principal de nitrógeno orgánico, como medio de enriquecimiento no selectivo que permitió desarrollar muchas bacterias heterótrofas.

Todas las soluciones fueron esterilizadas previamente en autoclave a 1,5 bar y $112{ }^{\circ} \mathrm{C}$ (Perry, R., Green, D., Maloney, J., 2001, p. 2-313) por un lapso de 15 minutos y adicionadas al inóculo en las cantidades necesarias para lograr una concentración final de 0,33 g/L de $\mathrm{N}$ y 0,066 g/L de P. Estos valores surgieron de la relación 5:1 que debe existir entre N y P, respectivamente (Carrillo L., 2003, p. 123).

Se incubó el inóculo en condiciones de oxígeno reducido usando un desecador cerrado con una vela encendida en su interior. Para corroborar que el oxígeno remanente se consumiese, se cubrió el fondo con lana de acero humedecida con agua destilada (Mitsuoka et al., 1969). Se colocó el desecador dentro de una incubadora a $37^{\circ} \mathrm{C}$. Al observarse la formación de una película superficial y la turbidez amarillenta, características del crecimiento, se dio por concluida la preparación del inóculo y se procedió a la etapa de aclimatación.

Para la aclimatación bacteriana se prepararon, por duplicado, medios de cultivo líquidos en Erlenmeyers de $100 \mathrm{~mL}$. La composición de los mismos fue: sales nutrientes del Medio Mínimo M9 (Nicklasson, 2008), glucosa al $20 \%$ m/v - co-sustrato - el inóculo bacteriano y las aguas madres en concentraciones crecientes de furfural (Pishgar et al., 2014). Previamente, 
se elevó el $\mathrm{pH}$ de las aguas madres con carbonato de sodio sólido $\left(\mathrm{Na}_{2} \mathrm{CO}_{3}\right)$ hasta $\mathrm{pH}=6$ (Boopathy and Daniels, 1991).

El M9, se adaptó de Koenig and Andreesen (1989), López et al. (2004) y Boopathy (2009), ya que sus estudios sugieren que ese medio mineral conduce a una buena aclimatación del consorcio bacteriano. El M9 se preparó con: $34 \mathrm{~g}$ de fosfato monoácido de sodio $\left(\mathrm{Na}_{2} \mathrm{HPO}_{4}\right)$ (Mallinckrodt Chemical Works, al 99,8\% de pureza), $15 \mathrm{~g}$ de fosfato diácido de potasio $\left(\mathrm{KH}_{2} \mathrm{PO}_{4}\right)$ (Mallinckrodt Chemical Works, al 99,0 \% de pureza), 2,5 g de cloruro de sodio $(\mathrm{NaCl})$ (Alcor, al 99,9\% de pureza), 0,5 g de cloruro de amonio $\left(\mathrm{NH}_{4} \mathrm{Cl}\right)$ (J.T. Baker Inc., al $99,7 \%$ de pureza) y ajustado a 1 litro.

Al momento de la siembra, se adicionaron $2 \mathrm{~mL}$ de glucosa $\left(\mathrm{C}_{6} \mathrm{H}_{12} \mathrm{O}_{6}\right)$ (Cicarelli, al 99,0 \%) al $20 \% \mathrm{~m} / \mathrm{v}, 0,1 \mathrm{~mL}$ de cloruro de calcio $\left(\mathrm{CaCl}_{2}\right) 1 \mathrm{M}$ (Merck, al 99,5\% de pureza), $2 \mathrm{~mL}$ de sulfato de magnesio $\left(\mathrm{MgSO}_{4}\right) 1 \mathrm{M}$ (Cicarelli, al 98,0 \% de pureza) $1 \mathrm{M}$ y $10 \mathrm{~mL}$ del inóculo en peptona.

Los medios de cultivo inoculados, se incubaron en una atmósfera con oxígeno reducido a una temperatura de $37^{\circ} \mathrm{C}$. Una vez apreciada la formación de una película superficial y la aparición de turbidez, se les agregó un $10 \% \mathrm{v} / \mathrm{v}$ de furfural en aguas madres equivalentes a $300 \mathrm{mg} / \mathrm{L}$ de furfural ; se los incubó en las condiciones ya citadas y en oscuridad, para prevenir que la oxidación fotoquímica (Zengh et al., 2015) diera lugar a falsos resultados. Verificado el desarrollo bacteriano, se procedió a realizar un repique. Se extrajeron $10 \mathrm{~mL}$ del medio con furfural al $10 \% \mathrm{v} / \mathrm{v}$, usado como inóculo, para ensayar concentraciones al 12, 15 y $20 \% \mathrm{v} / \mathrm{v}$ (600 mg/L de furfural), simultáneamente.

Al cabo de una semana, se seleccionó la concentración en la cual se apreció un mayor crecimiento y se realizó un nuevo repique. Se procedió de la misma manera en los ensayos posteriores, aclimatando los microorganismos a incrementos paulatinos en la concentración de furfural.

\section{Diseño, construcción y puesta en marcha del RALF}

El RALF fue proyectado para operar con el consorcio bacteriano extraído de los lodos y aclimatado a distintas concentraciones de furfural en aguas madres.

Se siguieron los pasos propuestos por Hidalgo and García Encina (2002) en cuanto a: selección del material soporte y sus características físicas (tamaño, forma, densidad, porosidad, esfericidad) y químicas (carácter inerte); elección de la expansión del lecho y cálculo de la velocidad superficial del líquido; dimensionamiento del lecho (diámetro, altura) y del sistema de bombeo.

\section{Características de la arena como soporte}

Se eligió la arena como material de soporte del lecho según las recomendaciones de Hidalgo and García Encina (2002). Los aspectos esenciales fueron:

- Partículas de pequeño tamaño y granulometricamente uniformes que brindan grandes superficies para el desarrollo del biofilm (Arnáiz et al., 2002).

- Fluidización homogénea en toda la longitud del lecho.

- Químicamente inerte y de bajo costo.

- Elevada resistencia al ataque físico, químico y biológico.

Por lo antedicho, la arena resultó ser un material apto que permitió un rápido arranque del equipo y el desarrollo de una biopelícula de gran estabilidad. Sin embargo, densidades 
muy altas de soportes como éste provocan un elevado consumo energético para alcanzar la velocidad de fluidización.

\section{Variables de diseño y operativas para la arena y el efluente}

Los parámetros de diseño del RALF se dedujeron de la ecuación de Ergun (McCabe, Smith, and Harriot, 2007, p. 177); se adoptaron variables de diseño y se calcularon variables operativas. Las primeras fueron: porosidad mínima de fluidización del lecho $\left(\varepsilon_{\mathrm{m}}\right)$, diámetro medio $\left(D_{p}\right)$, esfericidad $(\Phi)$, densidad de la partícula de arena $(\rho s)$, velocidad mínima de fluidización (Umf), viscosidad $\left(\mu_{\mathrm{f}}\right)$, densidad del efluente $\left(\rho_{\mathrm{f}}\right)$ y aceleración de la gravedad $(\mathrm{g})$.

Las variables operativas calculadas fueron: altura inicial del lecho de arena sin fluidizar $\left(\mathrm{L}_{\mathrm{m}}\right)$, porosidad del lecho totalmente expandido $(\varepsilon)$, altura total del lecho fluidizado $(\mathrm{L})$, velocidad operativa de fluidización $\left(\mathrm{U}_{\mathrm{op}}\right)$ y caudal operativo de fluidización del efluente $\left(\mathrm{Q}_{\mathrm{op}}\right)$.

En función de las características y recomendaciones citadas, se adoptaron valores tanto para la arena como para el efluente. El diámetro medio de partícula Dp se determinó mediante muestreo, con tamices estándar de la Serie Tyler (Foust, Wenzel, Clump, Maus, and Andersen, 2006, p. 723). Los números de malla abarcaron el intervalo de 200 a 400 micras tomando la fracción media de 270. La esfericidad de la arena $\Phi$ se adoptó usando la correlación entre la porosidad y la densidad de carga baja de la partícula (Foust A., et al., 2006, p. 635). La densidad de la arena $\rho$ s se extrajo de tablas (Nadeo and Leoni, 2013; Barreira Moreno, 2007).

En ausencia de datos experimentales para calcular la velocidad de fluidización mínima, la porosidad del lecho en estado de mínima fluidización $\varepsilon_{\mathrm{m}}$, se estimó de correlaciones. Levenspiel (1998) halló que la relación (1) se satisface para varios tipos de partículas:

$$
\frac{1}{\phi^{*} \varepsilon_{m}^{3}} \cong 14
$$

La velocidad mínima de fluidización Umf se calculó a partir de la porosidad mínima $\mathrm{em}$ reemplazando este parámetro en la ecuación (2) de Ergun:

Siendo:

$$
\frac{150\left(1-\varepsilon_{m}\right) * \mu_{f} * U_{m f}}{\phi^{2} * \varepsilon_{m}^{3} * D_{p}}+\frac{1,75 \rho_{s} * U_{m f}^{2}}{\varepsilon_{m}^{* 3} * D_{\rho}^{*} \phi}-g\left(\rho_{s}-\rho_{f}\right)=0
$$

$\mu_{\mathrm{f}}$ : viscosidad del efluente; $\rho_{\mathrm{f}}$ : densidad del efluente; g: aceleración de la gravedad y $\Phi$ : esfericidad de la arena.

La viscosidad $\mu_{\mathrm{f}}$ del efluente se midió a $37^{\circ} \mathrm{C}$ con un viscosímetro Brookfield y su densidad $\rho_{\mathrm{f}}$ se extrajo de tabla. Se calculó la porosidad del lecho totalmente expandido $\varepsilon$, a través de la ecuación (3):

$$
\left(1-\grave{O}_{m}\right) * L_{m}=(1-\varepsilon) * L \Rightarrow \varepsilon=1-\frac{L_{m}}{L} *\left(1-\varepsilon_{m}\right)
$$

Considerando que la altura inicial del lecho de arena sin fluidizar Lm es de $55 \mathrm{~cm}$ y la expansión del lecho deseada del 100\%, la altura total del lecho fluidizado L es de $1100 \mathrm{~cm}$.

Con la porosidad del lecho totalmente expandido $\varepsilon$, calculada en la ecuación (3) y reemplazada en la ecuación (2) de Ergun, se dedujo la velocidad operativa de fluidización Uop dentro del reactor.

El diámetro del reactor DR adoptado fue de $7 \mathrm{~cm}$ y la longitud total del reactor LR de 147 $\mathrm{cm}$, dimensiones óptimas para la caída de presión, según las experiencias de Ochieng et al. 
(2002). Por último, con $\mathrm{U}_{\mathrm{op}}$ y $\mathrm{D}_{\mathrm{R}}$, se calculó el caudal operativo de fluidización $\mathrm{Q}_{\mathrm{op}}$.

\section{Construcción e instalación del RALF}

La unidad experimental a escala piloto se construyó empleando una columna de PVC de $147 \mathrm{~cm}$ de longitud por $7 \mathrm{~cm}$ de diámetro interno, de acuerdo con Tavares et al. (1995) y Quintero Rendón (2011), constituyendo un reactor de 6 litros y un volumen total del sistema de 15 litros.

En la parte superior, el equipo se construyó con un aumento súbito de diámetro de 7 a 11 $\mathrm{cm}$ para lograr con la expansión brusca, disminuir la velocidad del flujo y evitar el arrastre de arena (Quintero Rendón, 2011). En el extremo inferior, se colocó un empaquetamiento de $10 \mathrm{~cm}$ de grava, obteniendo un flujo uniforme en la columna, evitando zonas del lecho sin expandir e impidiendo el reflujo (Hidalgo and García Encina, 2002).

La arena se lavó repetidas veces con agua destilada, para eliminar impurezas y luego se esterilizó a $550^{\circ} \mathrm{C}$ en horno mufla por 1 hora. Una vez fría, fue lavada nuevamente y secada a $105^{\circ} \mathrm{C}$ en estufa. El reactor se cargó con la fracción media de 270 micras de arena esterilizada, hasta una altura de $55 \mathrm{~cm}$.

El diseño contó con una línea de recirculación para lograr la velocidad óptima de fluidización y una expansión operativa del lecho del 100\%. En la línea de recirculación, se instaló un tanque pulmón de 5 litros, un filtro de espuma de poliuretano y una bomba centrífuga de $0.75 \mathrm{HP}$. La corriente de fluido, ingresó por la parte inferior del equipo impulsada por una bomba, imprescindible para asegurar la eficiencia del sistema de distribución.

El biogás producido durante la degradación biológica y el efluente tratado, egresaron del sistema por la parte superior. A la salida de la línea de reciclo superior, que conectaba el cuerpo del RALF con el tanque pulmón, se instaló un grifo para tomar muestras. El tanque pulmón cumplió dos objetivos: actuar como sedimentador de las partículas de soporte que pudieran ser arrastradas por la corriente de fluido y proporcionar una alimentación uniforme a la bomba. El filtro se instaló para retener las partículas de arena más finas, no sedimentadas en el tanque pulmón, y evitar dañar el rodete de la bomba. En la Figura 2, se muestra el RALF a escala piloto diseñado y emplazado con el que se trató el efluente sintético.

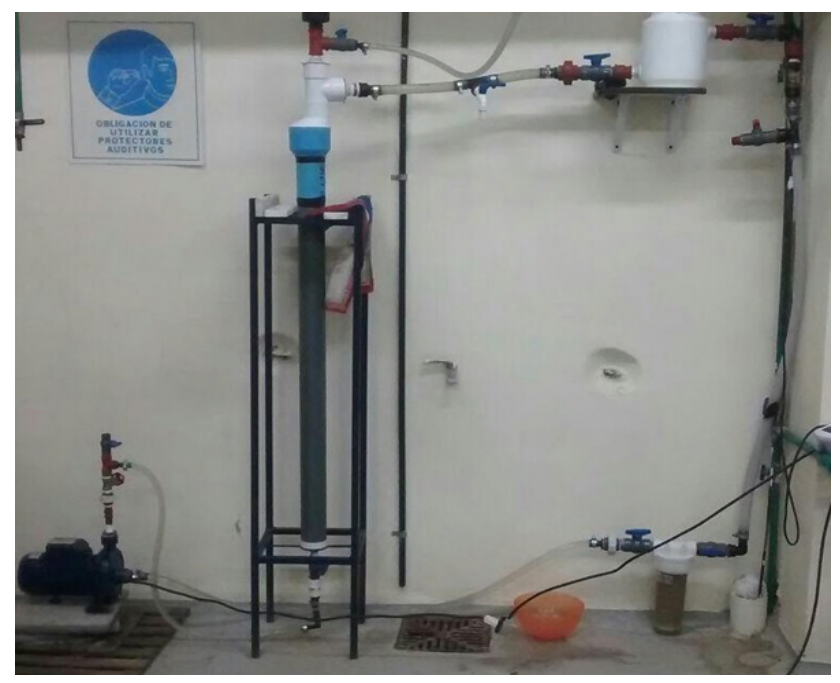

Figura 2. Reactor anaerobio de lecho fluidizado a escala piloto. 


\section{Puesta en marcha y monitoreo}

Una vez instalado el RALF, se realizó la prueba hidráulica con y sin presencia de arena para evaluar el correcto funcionamiento del mismo. El reactor con arena esterilizada en su interior se alimentó con el efluente sintético compuesto de: M9, glucosa, el inóculo bacteriano aclimatado y una concentración de $500 \mathrm{mg} / \mathrm{L}$ de furfural. El equipo no se operó con el efluente industrial real para eliminar variables que pudieran sacar de régimen el sistema. Por el mismo motivo y por tratarse de ensayos batch, no hubo necesidad de ecualizar el efluente.

Se lo puso en marcha a una velocidad de $26,6 \mathrm{~m} / \mathrm{h}$ y se tomó la primera muestra de efluente para realizarle el seguimiento correspondiente. El equipo funcionó de manera continua como un sistema cerrado por 55 horas consecutivas, a temperaturas entre 35 y $37{ }^{\circ} \mathrm{C}$. El efluente se consideró tratado cuando la degradación del furfural fue completa. Esto se verificó mediante el monitoreo periódico (cada 2 horas) de la concentración de furfural por cromatografía líquida de alto desempeño y de los parámetros fisicoquímicos más relevantes.

Para evaluar la perfomance del RALF, en las muestras obtenidas se determinaron las siguientes variables: $\mathrm{pH}$, Temperatura, Alcalinidad, Sólidos Suspendidos Volátiles (SSV), concentración de Furfural (FF), Demanda Química de Oxígeno (DQO), Nitrógeno Total Kjeldahl (NTK) y fósforo de fosfatos (P-PO ${ }_{4}^{3}$-).

Previo a cada análisis de la concentración de furfural por HPLC, se filtró la muestra, a través de un filtro de membrana de 0,45 micras, para eliminar la biomasa bacteriana.

\section{RESULTADOS Y DISCUSIÓN}

\section{Caracterización de las aguas madres}

Los valores recabados durante el muestreo de las aguas madres, realizado en Mayo, Septiembre y Noviembre se detallan en la Tabla 2:

\begin{tabular}{|c|c|c|c|c|c|c|c|c|c|c|}
\hline $\mathrm{pH}$ & $\begin{array}{c}\text { Conductiv } \\
(\mu \mathrm{S})\end{array}$ & $\begin{array}{c}\text { Turbidez } \\
(\mathrm{NTU})\end{array}$ & $\begin{array}{c}\text { Color } \\
(\mathrm{Pt}-\mathrm{Co})\end{array}$ & $\begin{array}{c}\mathrm{N}-\mathrm{NO2}- \\
(\mathrm{mg} / \mathrm{L})\end{array}$ & $\begin{array}{c}\mathrm{DBO5} \\
(\mathrm{mg} / \mathrm{L})\end{array}$ & $\begin{array}{c}\mathrm{DQO} \\
(\mathrm{mg} / \mathrm{L})\end{array}$ & $\begin{array}{c}\text { COT } \\
(\mathrm{mg} / \mathrm{L})\end{array}$ & $\begin{array}{c}\mathrm{ST} \\
(\mathrm{mg} / \mathrm{L})\end{array}$ & $\begin{array}{c}\mathrm{CT} \\
(\mathrm{NMP} / 100 \mathrm{~mL})\end{array}$ & $\begin{array}{c}\mathrm{CF} \\
(\mathrm{NMP} / 100 \mathrm{~mL})\end{array}$ \\
\hline 2.9 & 1114 & 113 & 651 & 0,05 & 14034 & 35884 & 10955 & 362 & Ausencia & Ausencia \\
\hline \pm 0.97 & \pm 103 & \pm 28 & \pm 102 & $\pm 0,05$ & \pm 2934 & \pm 14331 & \pm 7070 & \pm 143 & & \\
\hline
\end{tabular}

Tabla 2. Resultados de ensayos completos realizados sobre aguas madres.

Se observa que el pH es muy ácido - entre 2,7 y 3,4 - comparado con el intervalo de 5 a 9 estipulado por el Decreto $N^{\circ} 847$ de la Ley Provincial N 3230: "Código de Aguas" de la provincia del Chaco. Los valores obtenidos guardan una estrecha relación con el proceso de fabricación de furfural dado que, durante el mismo, se adiciona ácido sulfúrico como catalizador (Crönert and Loeper, 1969). Además, uno de los componentes que naturalmente poseen las aguas madres y les confiere acidez, es el ácido acético (Dunlop, 1948). Con ese nivel de pH, el efluente no puede ser volcado a ningún cuerpo receptor sin una neutralización previa ni utilizado en un tratamiento biológico por sus efectos deletéreos. La mayor parte de los sistemas biológicos prolifera entre valores de $\mathrm{pH}$ de 6,5 a 8,5. Valores superiores a 9 o inferiores a 5,8, limitan el desarrollo y la fisiología de los organismos (Bartram and Ballance, 1996).

Los valores medios de materia orgánica, medidos a partir de $\mathrm{DBO}_{5}$ y $\mathrm{DQO}$, son 
considerablemente superiores a los valores de vuelco establecidos por la ley citada, por lo que el efluente debe indefectiblemente ser tratado.

La relación $\mathrm{DBO}_{5} / \mathrm{DQO}$ permite calcular el índice de biodegradabilidad de un efluente (Area et al., 2010). Dicho índice es importante para evaluar, en este caso, la posibilidad de que los contaminantes contenidos en las aguas madres puedan ser removidos utilizando microorganismos. Un efluente biodegradable debe poseer un índice superior a 0,4 (Felissia et al., 2010). El valor obtenido de 0,39 , in dicaría que las aguas madres no serían biodegradables. No obstante, en los ensayos preliminares se determinó la posibilidad de biodegradación.

Otro parámetro fundamental evaluado fue la concentración de furfural residual en las aguas madres, cercana a $3.000 \mathrm{mg} / \mathrm{L}$. La normativa citada no detalla valores máximos de vuelco para el furfural. No obstante, se podría asumir como límite, un valor inferior al de ecotoxicidad CE50 - concentración efectiva que elimina al 50\% de la población de Daphnia magna - especificado en la ficha de datos de seguridad del furfural. La CE50 para este bioindicador, es igual a $29 \mathrm{mg} / \mathrm{L}$. La concentración final de furfural luego del tratamiento con el RALF fue de 0,4 mg/L, muy inferior al valor citado.

Con respecto a la carga microbiana representada por coliformes totales y coliformes fecales, el efluente presenta recuentos negativos. Esto resulta coherente con las características de las aguas madres cuyo $\mathrm{pH}$ fluctúa entre 2,7 y 3,4 y se extrae de la columna de destilación a una temperatura cercana a los $100^{\circ} \mathrm{C}$.

\section{Aclimatación de consorcios bacterianos a concentraciones crecientes de furfural contenido en aguas madres}

En un trabajo de investigación previo, se demostró que las bacterias extraídas de los lodos de los sedimentadores - comparadas con las provenientes de otras dos fuentes del sistema de tratamiento (Farías et al, 2015) -, manifestaron mayor tolerancia y crecieron en la concentración más elevada de furfural en aguas madres. Esto coincide con las investigaciones de López et al. (2004) y Zengh et al. (2015), quienes demostraron que las bacterias que están en contacto directo con el efluente a degradar, presentan una mejor performance.

En la Figura 3 se aprecia el progreso del inóculo bacteriano en peptona contenido en los Erlenmeyers.

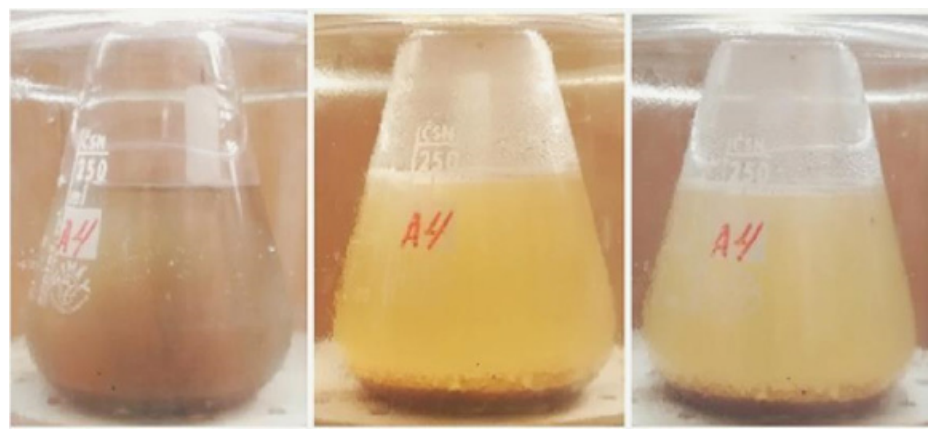

Figura 3. Crecimiento del inóculo bacteriano, con formación de la película superficial y enturbiamiento paulatino, desde el día 0 (izquierda) al 5 (derecha).

Se desarrollaron fases de aclimatación, con distintas concentraciones de furfural en 
aguas madres. A los medios de cultivo con furfural, se les adicionó el medio M9 combinado con y sin glucosa. Se observó desarrollo bacteriano, en ambos medios, aunque mayormente en el que contenía glucosa. Por ese motivo, se decidió trabajar con dicha combinación en las aclimataciones subsiguientes. A fin de prevenir la oxidación fotoquímica del furfural, sólo se sacó el desecador de la oscuridad para tomar las fotografías. En condiciones de oxígeno reducido, la aclimatación bacteriana prosperó hasta un $20 \% \mathrm{v} / \mathrm{v}$ de furfural en aguas madres, equivalente a 0,6 g/L. En la Figura 4 se observa el límite de desarrollo bacteriano obtenido a los 5 días de incubación.

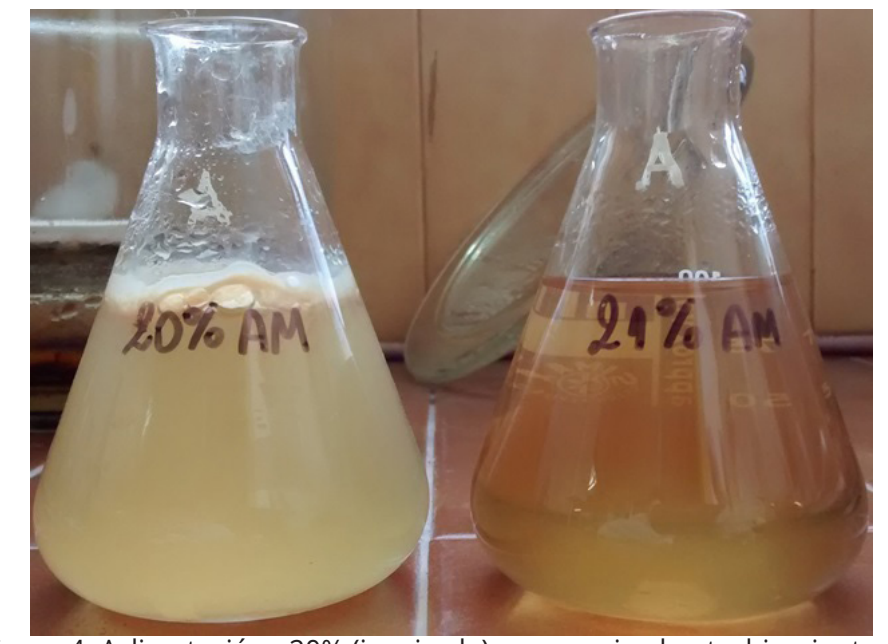

Figura 4. Aclimatación. 20\% (izquierda), se aprecia el enturbiamiento y la formación del biofilm. 21\% (derecha), ausencia de enturbiamiento.

Entre los diversos trabajos sobre degradación de furfural en condiciones anaerobias, Boopathy (2009), menciona que las concentraciones de furfural entre 0,096 y 1,15 g/L, inhiben a muchos microorganismos. Tomando como base lo citado, es dable decir que los 0,6 $\mathrm{g} / \mathrm{L}$ de furfural están comprendidos en ese rango por lo cual se apreció el desarrollo bacteriano; en cambio, en concentraciones superiores a la informada, no se detectó crecimiento.

Seguimiento de la operación del RALF y evaluación de su eficiencia

Se diseñó el RALF por ser el más adecuado para trabajar con un efluente de elevada carga orgánica y recalcitrante, como el furfural (Hidalgo and García Encina, 2002). Se operó con el consorcio bacteriano aclimatado a $500 \mathrm{mg} / \mathrm{L}$ de furfural, porque a esta concentración se apreció un crecimiento óptimo en los ensayos.

Se determinó el tiempo de retención hidráulico (TRH) para remover furfural y DQO. Asimismo, se verificó la evolución de la biomasa bacteriana monitoreando los sólidos suspendidos volátiles. Se construyeron los siguientes gráficos para analizar el desempeño del RALF.

\section{A. Disminución de furfural, DQO Y SSV en el RALF función del TRH}

La Tabla 3 indica la variación de las concentraciones de furfural, DQO y SSV al inicio (TRH $=0 \mathrm{~h}) \mathrm{y}$ al final del proceso $(\mathrm{TRH}=55 \mathrm{~h})$. 


\begin{tabular}{|c|c|c|c|}
\hline \multirow{2}{*}{ TRH [h] } & \multicolumn{3}{|c|}{ Concentraciones [ppm] } \\
\cline { 2 - 4 } & FF & DQO & SSV \\
\hline 0 & 500 & 5.603 & 50 \\
\hline 3 & 443 & 5.247 & 58 \\
\hline 7 & 397 & 5.177 & 184 \\
\hline 20 & 0,460 & 4.994 & 72 \\
\hline 31 & 0,409 & 4.661 & 45 \\
\hline 44 & 0,408 & 4.655 & 2 \\
\hline 50 & 0,408 & 4.638 & 0 \\
\hline
\end{tabular}

Tabla 3. FF, DQO y SSV vs. TRH.

Los resultados denotan que, en un TRH de 20 h, hubo una disminución radical de la concentración de furfural y un descenso no tan pronunciado de la DQO.

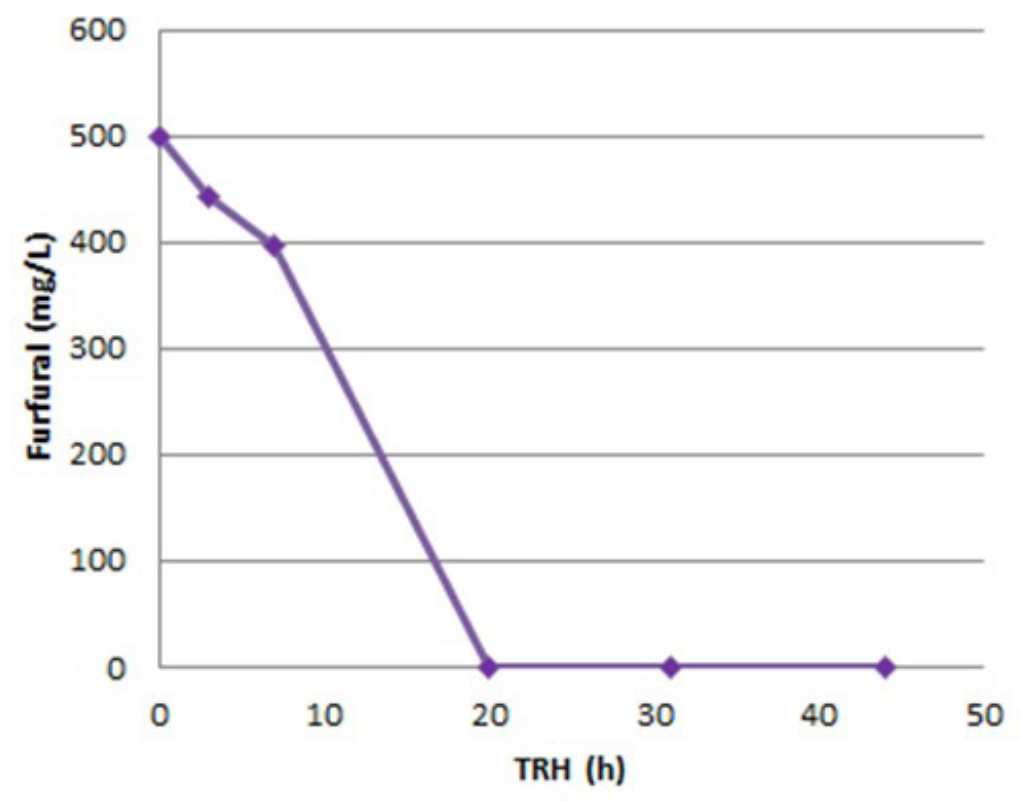

Figura 5. Disminución de FF en el RALF.

La Figura 5, indica un descenso sustancial de la concentración de furfural - de 500 a 0,4 $\mathrm{mg} / \mathrm{L}$ - en un TRH de $20 \mathrm{~h}$. 


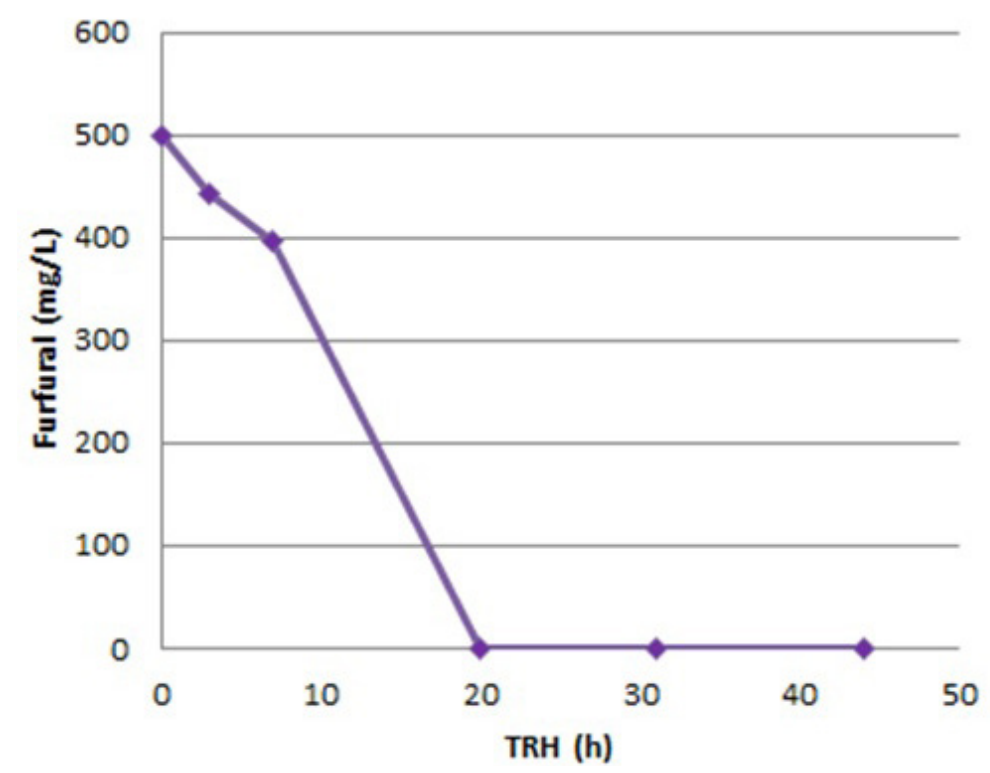

Figura 6. Disminución de DQO en el RALF

La Figura 6 muestra el decrecimiento paulatino de la concentración de DQO, durante las 55 horas en que funcionó el RALF, pasando de 5.603 a $4.638 \mathrm{mg} / \mathrm{L}$.

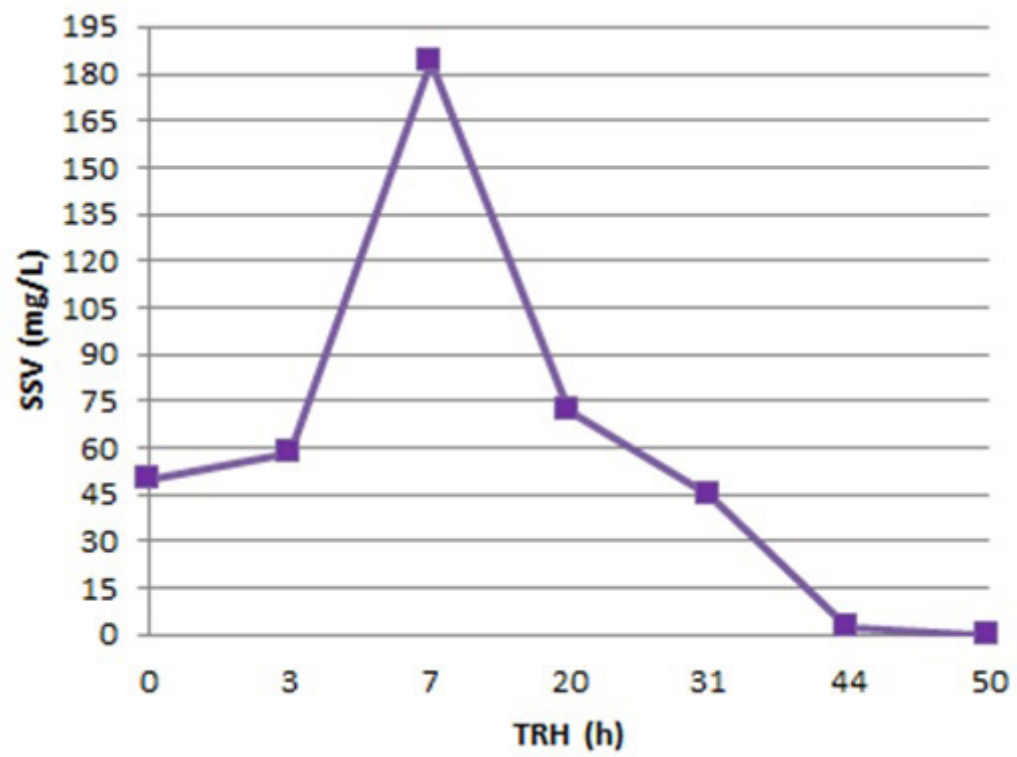

Figura 7. Variación de SSV en el RALF

En la Figura 7 se observa la evolución de los SSV - de 50 a 184 mg/L -, que permitieron controlar el crecimiento del consorcio bacteriano. Se notó un ascenso inicial y luego un descenso pronunciado conforme la biomasa comenzó a decrecer. En un TRH entre 7 y 20 horas, la concentración bajó abruptamente de 184 a $72 \mathrm{mg} / \mathrm{L}$. A partir de allí, el decrecimiento fue 
más suave.

En todos los gráficos se observa un descenso acentuado de la concentración de furfural y no tan marcado de DQO. Asimismo, en las primeras horas de funcionamiento del biorreactor, hay un incremento de la biomasa bacteriana evidenciada a través de los SSV. En las horas subsiguientes, se apreció un retroceso en el desarrollo del consorcio bacteriano, al declinar ese parámetro.

En un TRH de 3 horas, la concentración de furfural descendió suavemente, de 500 hasta $397 \mathrm{mg} / \mathrm{L}$; asimismo, la de DQO declinó levemente de 5.603 a $5.247 \mathrm{mg} / \mathrm{L}$ y los SSV ascendieron de 50 a $58 \mathrm{mg} / \mathrm{L}$. Las disminuciones poco acentuadas del furfural y la DQO, están relacionadas con el ligero aumento de los SSV. Las causas de ello podrían ser: el período de latencia en el que consorcio bacteriano debe adaptarse al nuevo medio, adherirse a la superficie de la arena y acumularse, y luego crecer (Shieh and Keenan, 1984). Estas etapas de la curva de crecimiento microbiano concuerdan con lo señalado por dichos autores.

En un TRH entre 3 y 7 horas, la concentración de furfural disminuyó marcadamente desde 397 a 0,46 mg/L; la DQO no decreció notablemente, pasando de 5.247 a $5.177 \mathrm{mg} / \mathrm{L}$ y los SSV aumentaron considerablemente desde 50 hasta $184 \mathrm{mg} / \mathrm{L}$. Puede vincularse este comportamiento con la etapa de crecimiento exponencial de la curva de crecimiento: el incremento de los SSV representaría esa etapa en el crecimiento del consorcio y su multiplicación. Asimismo, indicaría que el consorcio utilizó el furfural como fuente principal de energía, degradándolo.

\section{B. Eficiencia de remoción de FF Y de DQO en función del TRH}

En la Figura 8 se puede inferir que, en un TRH de 20 horas, se obtuvo el porcentaje de remoción de furfural más elevado del ensayo con una eficiencia del 99,92\%. En contraste, la DQO reveló una tendencia poco pronunciada al descenso, que se mantuvo hasta el final. Durante la última etapa de operación del reactor se alcanzó una concentración final de 4.638 $\mathrm{mg} / \mathrm{L}$, con una eficiencia de remoción del 17\%.

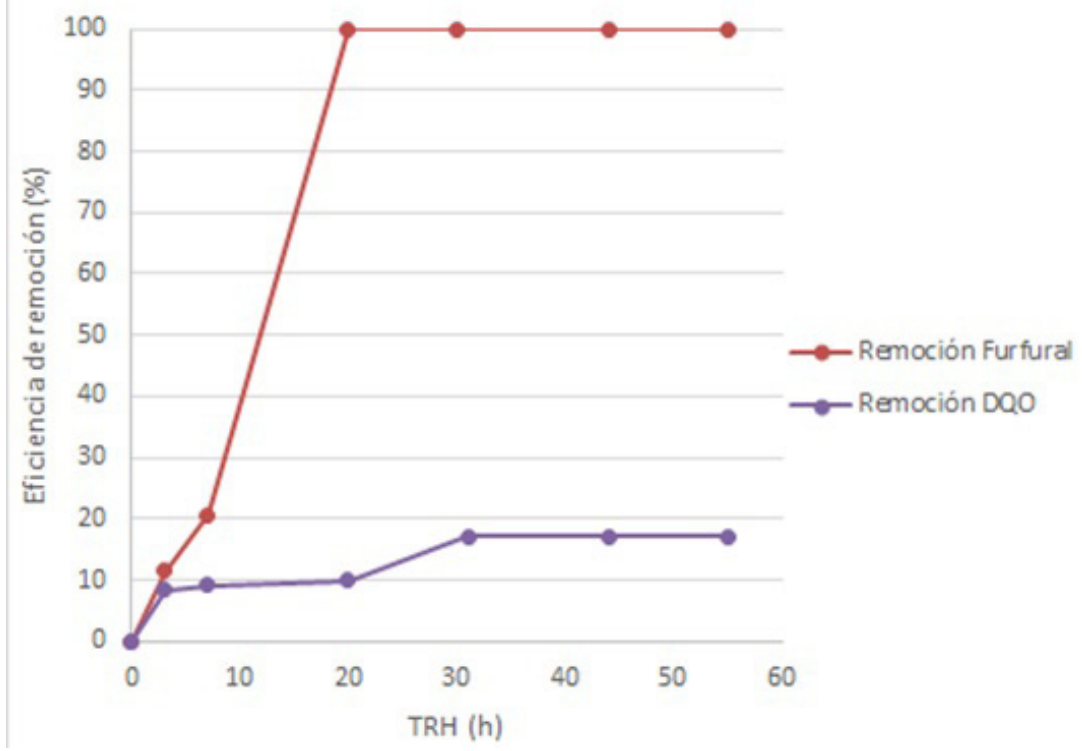

Figura 8. Porcentaje de remoción de FF y DQO en el RALF 
La degradación observada en el furfural y la DQO, y el descenso notable en los SSV - de 72 a $44 \mathrm{mg} / \mathrm{L}$ - a las 20 horas de operación, podrían asociarse con la transición de la fase estacionaria a la de decaimiento microbiano. Puede inferirse que el consorcio no sólo se quedó sin fuente de energía para seguir creciendo, sino que comenzó la fase de muerte celular.

\section{CONCLUSIONES}

Se pueden resaltar dos características del efluente aguas madres - cola de la primera columna de destilación - del proceso de fabricación de furfural: bajos valores de $\mathrm{pH}$ y niveles elevados de DBO5, DQO, ácido acético y furfural residual. Estos compuestos transforman al efluente en recalcitrante - resistente a la biorremoción - y potencialmente tóxico para la biota acuática, complicando tratarlo con microorganismos. Sin embargo, el índice de biodegradabilidad indicó la posibilidad de presencia de carga orgánica degradable o al límite de su biodegradabilidad.

Por las razones ya expuestas, el efluente no puede ser volcado a un cuerpo receptor sin un tratamiento previo.

El proceso de aclimatación bacteriana, con concentraciones crecientes de furfural y en condiciones de oxígeno reducido, demostró que el consorcio puede desarrollarse en medios con hasta $600 \mathrm{mg} / \mathrm{L}$ de furfural, utilizándolo como fuente de energía; asimismo, logró aumentar la eficiencia bacteriana para que, al inocularlas dentro del reactor, resistieran y removieran el furfural.

Se comprobó la eficacia del Reactor Anaerobio de Lecho Fluidizado diseñado y construido al lograr, en un tiempo de retención hidráulico de 20 horas, remociones de furfural y DQO de 99,92 y $17 \%$, respectivamente.

Finalmente, luego de sucesivas aclimataciones, el consorcio bacteriano puede degradar efluentes que contengan compuestos agresivos como el furfural.

La continuidad de este trabajo se proyecta a partir de los ensayos de remoción a escala piloto, manteniendo las condiciones encontradas como óptimas. No obstante, se usará el furfural puro, a fin de demostrar la capacidad de remoción en las condiciones normales del proceso. 


\section{REFERENCIAS}

APHA; AWWA and WEF (2005). Standard Methods for the Examination of Water \& Wastewater, American Public Health Association, Washington, D.C.

Area, M.; S. Ojeda; O. Barboza; D. Bengoechea y F.E. Felissia (2010). "Tratamientos aplicables para la reducción de la DQO recalcitrante de efluentes de pulpados quimimecánicos y semiquímicos (revisión)", Revista de Ciencia y Tecnología, 12 (13), 4-12. Disponible en: https://www.researchgate.net/publication/260770641_Tratamientos_ aplicables_para_la_reduccion_de_la_DQO_recalcitrantede_efluentes_de_pulpados_ quimimecanicos_y_semiquimicosrevision

Arnáiz, C.; M. Medialdea; J. Lebrato y J. Gutiérrez (2002). "Eliminación biológica de contaminantes. Reactores de tercera generación", Ingeniería Química, 391, 115-120. de

Bartram, J. and Ballance, R. (1996). Water Quality Monitoring: a practical guide to the design and implementation of fresh water quality studies and monitoring programmes, CRC Press.

Barreira Moreno, V. (2007). "Estudio hidrodinámico de un lecho fluidizado", Tesis (Maestría), Universidad Carlos III de Madrid, España. Disponible en: http://e-archivo.uc3m. es/bitstream/handle/10016/1161/pfc_lecho_fluidizado.pdf?sequence=1

Boopathy, R. and L. Daniels (1991). "Isolation and characterization of a furfural degrading sulfate-reducing bacterium from an anaerobic digester", Current Microbiology, 23(6), 327-332. Disponible en: https://www.researchgate.net/publication/226380349_Isolation_ and_characterization_of_a_furfural_degrading_sulfate-reducing_bacterium_from_an_ anaerobic_digester

Boopathy, R. (2009). "Anaerobic biotransformation of furfural to furfuryl alcohol by a methanogenic archaebacterium", International Biodeterioration \& Biodegradation, 63(8), 1070-1072. Disponible en: https://www.researchgate.net/publication/248436824_ Anaerobic_biotransformation_of_furfural_to_furfuryl_alcohol_by_a_methanogenic_ archaebacterium

Brune, G., S. Schoberth and H. Sahm (1983). "Growth of a strictly anaerobic bacterium on furfural (2-furaldehyde) ", Applied and Environmental Microbiology, 46(5), 1187-1192. Disponible en: http://www.ncbi.nlm.nih.gov/pmc/articles/PMC239539/pdf/aem00168-0231

Carrillo, L. (2003). Microbiología Agrícola. Los hongos de los alimentos y forrajes, Universidad Nacional de Salta, Argentina.

Crönert, H. and Loeper, D. (1969). "New industrial paths in the continuous production of furfural", Escher Wyss News, 2, 69-77.

Dunlop, A. (1948). Furfural formation and behavior, Industrial \& Engineering Chemistry, 40(2), 204-209.

Farhan, M., Chinhong, P., Keenan, J., and Shieh, W. (1997). "Performance of anaerobic reactors during pseudo-steady-state operation", Journal. Chem. Tech. Biotech., 69 (1), 4557. Disponible en: https://www.researchgate.net/publication/243813476_Performance_of_ Anaerobic_Reactors_during_Pseudo-Steady-State_Operation 
Farías, A., Utgés, E. E., Tenev, M., Hervot, E., Utgés, E. M., Baccaro, J., and Mlot, Z. (2015). "Ensayo de crecimiento bacteriano en un efluente industrial recalcitrante", Actas del Congreso V Proyecto Integrador para la Mitigación de la Contaminación Atmosférica (PROIMCA) y III Congreso del Proyecto Integrador para la Determinación de la Calidad del Agua (PRODECA), La Rioja, Argentina, 11 al 13 de agosto, 1-14.

Felissia, F., Barboza, O., Bengoechea, I., And Area, M. (2010). "Reducción de la DQO recalcitrante de efluentes de pulpados semi-químicos mediante precipitación química", Revista de Ciencia y Tecnología, 13. Disponible en: https://www.researchgate.net/ publication/262655939_Reduccion_de_la_DQO_recalcitrante_de_efluentes_de_pulpados_ semiquimicos_mediante_precipitacion_quimica

Fernández Linares, L., Rojas Avelizapa, N., Roldán Carrillo, T., Ramírez Islas, M., Zegarra Martínez, H., Uribe Hernández, R., Reyes Ávila, R., Flores Hernández, D., and Arce Ortega, J. (2006). "Manual de técnicas de análisis de suelos aplicadas a la remediación de sitios contaminados". Disponible en: http:// www.inecc.gob.mx/descargas/publicaciones/509.pdf

Foust, A., Wenzel, L., Clump, C., Maus, L., and Andersen, L. (2006). Principio de Operaciones Unitarias, Compañía Editorial Continental, México.

Hareland, W., Crawford, R., Chapman, P. and Dagley, S. (1975). "Metabolic function and properties of 4-hydroxyphenylacetic acid 1-hydroxylase from Pseudomonas acidovorans", Journal of Bacteriology, 121(1), 272-285. Disponible en: http://jb.asm.org/content/121/1/272. full.pdf

Hidalgo, M., and García Encina, P. (2002). "Reactores biológicos de lecho fluidizado". Ingeniería química, 391, 122-133. Disponible en: https://www.researchgate.net/ publication/296149847_Reactores_biologicos_de_lecho_fluidizado

Hidalgo, M., Del Alamo, J., Hernández, M. and Irusta, R. (2003). Tratamiento de la fracción líquida del purín porcino en bio-reactores anaerobios de lecho fluidizado, Ingeniería del agua, 10(2), 127-133. Disponible en: http://www.polipapers.upv.es/index.php/IA/article/ viewFile/2579/2561

International Furano Chemicals B.V. (2003). "Furfural", Ficha de datos de seguridad. Disponible en: https://www.furan.com/_resources/downloads/10195es_rev6.pdf

Koenig, K. and J. Andreesen, 1989. "Molybdenum involvement in aerobic degradation of 2furoic acid by Pseudomonas putida Fu1", Applied and Environmental Microbiology, 55(7), 1829-1834. Disponible en: https://www.ncbi.nlm.nih.gov/pmc/articles/PMC202958/pdf/ aem00100-0175.pdf

Levenspiel, O. (1998). Flujo de fluidos e intercambio de calor, Editorial Reverté S.A. Barcelona, España.

López, M., Nichols, N., Dien, B., Moreno, J. and Bothast, R. (2004). "Isolation of microorganisms for biological detoxification of lignocellulosic hydrolysates", Applied Microbiology and Biotechnology, 64(1), 125-131. Disponible en: https://www.researchgate. net/publication/6348676_Isolation_of_microorganisms_for_biological_detoxification_of_ lignocellulosic_hydrolysates

McCabe, W., Smith, J. and Harriot, P. (2007). Operaciones Unitarias en Ingeniería Química, McGraw-Hill/Interamericana Editores, México. 
Mitsuoka, T., Morishita, Y., Terada, A. and Yamamoto, S. (1969). "A Simple Method ("Plate-in-Bottle Method") for the Cultivation of Fastidious Anaerobes", Japanese Journal of Microbiology, 13(4), 383-385. Disponible en: http://onlinelibrary.wiley.com/ doi/10.1111/j.1348-0421.1969.tb00482.x/pdf

Nadeo, J., y Leoni, A. (2016). "Introducción a algunas propiedades fundamentales de los suelos", Disponible en: http://docplayer.es/5768041-Introduccion-a-algunas-propiedadesfundamentales-de-los-suelos.pdf

Nicklasson, M. (2008). "Studies on the expression and regulation of enterotoxins and colonization factors in enterotoxigenic Escherichia coli (ETEC)". Disponible en: https:// gupea.ub.gu.se/bitstream/2077/9610/1/EPUBRAM.pdf

Ochieng, A., Ogada, T., Sisenda, W. and Wambua, P. (2002). "Brewery wastewater treatment in a fluidised bed bioreactor", Journal of Hazardous Materials, 90(3), 311-321. Disponible en: https://www.sciencedirect.com/science/article/pii/S0304389401003739

Pagliettini, L., 2014. Los recursos hídricos. Instrumentos económicos para su gestion, Imago Mundi, Buenos Aires, Argentina.

Perez, M., Romero, L. I., and Sales, D. (1998). "Comparative performance of high rate anaerobic thermophilic technologies treating industrial wastewater", Water Research, 32(3), 559-564. Disponible en: https://www.researchgate.net/publication/222032292_ Comparative_performance_of_high_rate_anaerobic_thermophilic_technologies_treating_ industrial_wastewater

Perry, R., Green, D., Maloney, J. (2001). Manual del Ingeniero Químico, McGraw-Hill/ Interamericana de España, S.A.U., Madrid, España.

Pishgar, R., Najafpour, G., Neya, B., Mousavi, N., and Bakhshi, Z. (2014). "Effects of organic loading rate and hydraulic retention time on treatment of phenolic wastewater in an anaerobic immobilized fluidized bed reactor", Journal of Environmental Engineering and Landscape Management, 22(1), 40-49. Disponible en: https://www.tandfonline.com/doi/abs /10.3846/16486897.2013.800079

Puyal, P. (2010). Diseño preliminar para el tratamiento de efluente de alta carga generado por actividad del procesamiento de tanino vegetal a partir del quebracho, New England Systems S.A, Informe Técnico para Indunor S.A, Chaco, Argentina.

Quintero Rendón, L (2011). "Evaluación del tratamiento biológico para la remoción del color índigo del agua residual industrial textil, por un consorcio microbiano, en lecho fluidizado", Tesis (Maestría), Universidad Nacional de Colombia, Medellín.

Ran, H., Zhang, J., Gao, Q., Lin, Z., and Bao, J. (2014). "Analysis of biodegradation performance of furfural and 5-hydroxymethylfurfural by Amorphotheca resinae ZN1", Biotechnology for biofuels, 7(1), 51. Disponible en: https://biotechnologyforbiofuels. biomedcentral.com/articles/10.1186/1754-6834-7-51

Shieh, W. and Keenan, J (1986). "Fluidized bed biofilm reactor for wastewater treatment", Advances in Biochemical Engineering, Biotechnology, 33, 131-169. Disponible en: https:// www.researchgate.net/publication/225524359_Fluidized_Bed_Biofilm_Reactor_for_ Wastewater_Treatment

Tavares, C., Sant'Anna, G. and Capdeville, B. (1995). "The effect of air superficial velocity on 
biofilm accumulation in a three-phase fluidized-bed reactor", Water Research, 29(10), 22932298. Disponible en: https://www.researchgate.net/publication/223713037_The_effect_of_ air_superficial_velocity_on_biofilm_accumulation_in_a_three-phase_fluidized-bed_reactor Wierckx, N., Koopman, F., Ruijssenaars, H. and De Winde, J. (2011). "Microbial degradation of furanic compounds: biochemistry, genetics, and impact", Applied microbiology and biotechnology, 92(6), 1095-1105. Disponible en: https:/www.researchgate.net/ publication/51749221_Microbial_degradation_of_furanic_compounds_Biochemistry_ genetics_and_impact

Zheng, D., Bao, J., Lu, J. and Gao, C. (2015). "Isolation and characterization of a furfuraldegrading bacterium Bacillus cereus sp. strain DS1", Current microbiology, 70(2), 199-205. Disponible en: https://www.researchgate.net/publication/266570451_Isolation_and_ Characterization_of_a_Furfural-Degrading_Bacterium_Bacillus_cereus_sp_Strain_DS1 